\title{
Welcome to Qualitative Research in Medicine \& Healthcare
}

\author{
Mariaelena Bartesaghi \\ Department of Communication, University of South Florida, Tampa, FL, USA
}

On behalf of the authors, the reviewers, the editorial staff and our wonderful Editorial and Advisory Boards I extend a warm welcome to our first issue of Qualitative Research in Medicine and Healthcare (QRMH)! I am lucky to be working with so many great people, and dedicated to making this a great place to publish.

With many qualitative research journals already on the academic scene, and a good amount of these in the areas of health communication, healthcare, and medicine a new journal is a risky proposition. As our aims and scope promise, it is nonetheless a vital and crucial undertaking. As the articles in this first issue demonstrate, QRMH is true to its promise of interdisciplinarity; four of its five pieces are collaborations by scholars sand practitioners in medicine, nursing, communication, biology, theology, international affairs and conflict resolution. And all of the articles raise complex queries, tell difficult stories or ask the complex and uncomfortable questions for which qualitative research is best equipped.

As many of you already know, qualitative research is not for the faint of heart. It is reflexive, positioned and like life itself, often messy and focused not on producing easy answers but on the very process of questioning. It is, at best, acutely aware its ontological consequentiality. Unlike research studies under positivist or post-positivist auspices, true qualitative research does not separate the observer from the lived experience of those whom she observes.

Correspondence: Mariaelena Bartesaghi, Department of Communication, University of South Florida, 4202 E Fowler Ave CIS 3057, Tampa, 33620 FL, USA.

Tel: +1.813.974.2145 - Fax: +1.813.974.6817.

E-mail: mbartesaghi@usf.edu

Key words: Qualitative Research in Medicine \& Healthcare; Editorial; Interdisciplinarity.

Received for publication: 9 February 2017.

Accepted for publication: 9 February 2017

This work is licensed under a Creative Commons Attribution NonCommercial 4.0 License (CC BY-NC 4.0).

CCopyright M. Bartesaghi, 2017

Licensee PAGEPress, Italy

Qualitative Research in Medicine \& Healthcare 2017; 1:i-ii

doi:10.4081/qrmh.2017.6642
Rather, it is by understanding the ways in which our own research practices bring forth the very world in which we live that qualitative researchers have a stake in understanding the very reflexive dynamics of how we constitute the world makes us.

Consider the traditional process of knowledge construction in medicine and healthcare and how, in these very social and human sciences, we unproblematically take notions of scientific evidence as detached from the very measurements, screenings, and processes of lived experience in which knowledge-making is situated. Data, findings, reports are always written in the third person omniscient language of science, concealing writers, bodies, lives. We try to fit ourselves into the spaces offered by questionnaires, rather than finding questionnaires designed to fit us.

Though evidence-based has become a popular phrase, for example, it works by pronominal omission; and yet it is always evidence for someone, by someone, and in a particular context with very real and life changing consequences. By the same token, that of patient (including the popular patient-centered), disadvantage, vulnerable, and so on are constructs - that is, categories that create the very situations they purport to describe. By way of our research findings and discussions, these categories can either re-enter the world as natural, or we may use research as a process in which to examine the social dynamics of what it means for these terms to categorize and create what Wittgenstein called forms of life, that is, to describe, as well as prescribe conditions of our very being and courses of action that implicate courses of actions, policies, social change.

As Erin Castelloe tells us in an intensely personal and beautifully written opening article (and the second part to this first one is already in the works!) she is a woman at a crossroads, facing important decisions as to how to (re)construct her career and personal life. Metaphorically, working in healthcare is a matter of always being at a crossroads. Medicine, she writes, is

practiced by imperfect human beings, most of whom are dangerously overworked.

The stories that enrage me are those in which doctors dismiss people's concerns without a complete

assessment: the man without insurance who is obviously having a heart attack but is discharged from urgent care 
(...); the young woman with new-onset, nocturnal seizures who is diagnosed with a supra-tentorial issue (anxiety and/or personality disorder) without a neurological exam, let alone a sleep study and nocturnal electroencephalogram (EEG). ${ }^{1}$

In a sometimes difficult to read, and yet relentlessly hopeful piece, life partners and co-authors Davidson and Davidson appear to engage in a symbolic dialogue with Castelloe, and with the notion of evidence itself, when narrating about their own crossroads, in a moment of waiting what they knew would be difficult news about their unborn baby. They write how:

the concept of evidence based medicine rests upon the knowledge of what treatments have worked in the past and are predicted to work in the future. However, when there is no evidence and no one can predict what will happen, it is easy to panic, avoid the situation or despair [yet] There is life in the not-knowing. ${ }^{2}$

In qualitative studies, narratives are not the subject of examination, but a research method in itself. In making sense and giving order to experience, researchers engage us in moments of social life in ways both vivid and situated, setting aside canonical notions of generalizability in favor of true validity - or the ability of personal experience to speak truth to anonymity, and to demonstrate how scholarship is always personal.

In this vein, the fascinating study by Riva-Mossman and Verloo notes that seniors' stories of hope and healthy aging reflexively create the very hopeful and healthful conditions they narrate into being. The authors note that:

seniors may consider themselves as healthy within their own meaning systems irrespective of chronic illness and that the most appropriate people to define what healthy aging means are seniors themselves. ${ }^{3}$

Much like Riva-Mossman and Verloo, the analysis by Smith-Cavros, Avoki-Wuaku, Wuaku and Bhullari endeavors to understand the social accounting practices of a population in order to make bottom up policy changes.

Smith-Cavros et al.'s rich ethnographic and interview analysis of the culturally situated meaning of health insurance to village elders in rural Ghana reveals that though insurance may sound like a good thing in theory, its practicality leaves a lot to be desired. Speaking to their own research commitments, the authors write that their project:

is shaped by our position (as a research team) that healthcare is a human right and that a properly functioning and funded program providing universal coverage to all citizens (with hands-on citizen participation) can promote improved physical and social well-being. ${ }^{4}$
The study sheds new light in the way policy makers may employ accounts to make effective changes in communities where health insurance is not used as proponents wish it could be.

The final article in this issue, by Gathercoal, Gathercoal, Seegobin, and Hadley combines quantitative and qualitative approaches in an innovative and creative research design. The authors challenge the view that disabilities are either romantic conditions that render those affected with them special in some way or, on the other hand, horrible biological or physical handicaps that dehumanize them instead of seeing these individuals as ordinary people facing extraordinary, and often society-created obstacles. ${ }^{5}$ I find no better way to conclude this introduction than to use these authors commentary on reflexivity, constitutiveness, and consequentiality in research, and the fearlessness of qualitative researchers to be aware of these issues. As Gathercoal et al. so aptly note,

\section{Even traditional concepts such as effective come embedded with specific cultural and social perspectives with biases, adopting positions which take for granted ill-defined social goals and unintended consequences. Who, for example, gets to determine just what is best for both clinicians and for clients? ${ }^{5}$}

In leaving you to this and many more thought provoking questions and insightful studies that compose this first issue, I extend an invitation to all of you who are reading that you will submit to our journal, and join in the exciting, innovative, rigorous and spirited research conversations that will take place in this forum.

\section{References}

1. Castelloe E. Finding myself in Medicine. Qualit Res Med Healthe 2017;1:6301.

2. Davidson LG, Davidson A. The anvil: a crushing conversation. Qualit Res Med Healthc 2017;1:6086.

3. Riva-Mossman X, Verloo H. Explorative healthy aging approaches fostering social innovation: thematizing life course narratives of older women participating in a documentary film. Qualit Res Med Healthc 2017;1:6199.

4. Smith Cavros E, Avotri-Wuaku J, Wuaku A, Bhullar A. Oh, as for the Health Insurance... it's good, but...: rural elders in Agate, Ghana, discuss the National Healthcare Insurance Scheme. Qualit Res Med Healthc 2017;1:6300.

5. Gathercoal RO, Gathercoal KA, Seegobin W, Hadley S. Nurturing constructive change that works: a critical theory-informed model for transforming health service psychologists' views of people with disabilities. Qualit Res Med Healthc 2017;1:6391. 